\title{
Adherence to the current guidelines in the management of paraquat poisoning; an audit
}

\author{
Jayasinghe $\mathbf{S S}^{1,2}$, Fernando $\mathbf{A}^{1}$ \\ ${ }^{\prime}$ Department of Pharmacology, Faculty of Medicine, University of Ruhuna, Sri Lanka \\ ${ }^{2}$ South Asian Clinical Toxicology Research Collaboration, Department of Medicine, Faculty of Medicine, \\ University of Peradeniya, Sri Lanka
}

Correspondence: $\quad$ Dr.S.S. Jayasinghe;

Mobile: +94 77 2988312; e-mail: sudheerasj@yahoo.com

\begin{abstract}
Background: Self-poisoning with paraquat (PQ) is a major health problem with $60-70 \%$ fatality. Fuller's earth is the mainstay of therapy as other treatment modalities are controversial. Current management guidelines of paraquat poisoning recommend the administration of Fuller's earth / activated charcoal until they are detected in stools and also immunosuppression therapy. The aim of the study was to look at the adherence to the existing guidelines in the management of PQ poisoning by the ward staff.
\end{abstract}

Methods: In this cross-sectional study consecutive patients admitted to two selected hospitals due to PQ poisoning were recruited. Current practice in management of PQ poisoning in these hospitals was compared with the National guidelines.

Results: There were 145 patients (111 males) admitted with paraquat poisoning during the study period. Fuller's earth was given to $130(89.6 \%)$ patients. One patient refused and one died before the treatment. Twelve (8.3\%) patients did not receive Fuller's earth. Among them five died with the median of 3 (range 1-13) days after the hospital admission. Nineteen (14.6\%) patients out of 130 who received PQ did not notice Fuller's earth in their stool. Forty patients either did not observe Fuller's earth in their stools or the data was not available. Eighty four (58\%), 14 (10\%) and 57 (39\%) patients received cyclophosphamide, dexamethasone and methylprednisolone, respectively.

Conclusion: Among the patients who received Fuller's earth at least 14\% did not fulfill the criteria of proper administration. Education of health care people on administration of Fuller's earth may be required. Even though immunosuppression therapy is controversial, more than $50 \%$ of patients received it.

Keywords: Herbicide, Immunosuppression, Paraquat, Therapeutics

\section{Introduction}

Paraquat (PQ) (1,1' - dimethyl-4,4' - dipyridyl ) is a bipyridyl compound. It was first marketed in 1962 as a broad-spectrum, non selective and contact herbicide after having been first described by Weidel and Rosso in $1882(1,2)$. Self-poisoning with PQ is a major health problem as it has the highest individual case fatality rate of around $65 \%$ for any given poison in Sri Lanka (3). PQ is highly corrosive. It is absorbed poorly after inhalation but is extremely toxic if ingested. After PQ ingestion, mucosal oedema, burns or ulceration may be seen in the mouth, oesophagus, stomach and intestines. Death usually occurs within 48 hours of ingestion of 50 $\mathrm{mg} / \mathrm{kg}$ or more than $20 \mathrm{ml}$ of $20 \%$ preparation of PQ (4). At lower doses death may be delayed for several weeks (1). Toxicity of paraquat is due to the pulmonary accumulation of the bipyridyl compound. PQ is transported actively into 
pulmonary cells resulting in pulmonary oedema or fibrosis. The major cause of death in PQ poisoning is respiratory failure due to an oxidative insult to the alveolar epithelium with subsequent obliterating fibrosis (4).

The principles of pharmacological management of PQ poisoning include Fuller's earth or activated charcoal, immunosuppressants (cyclophosphamide, dexamethasone and methyl prednisolone) and fluids. The role of immunosuppressants is not completely clear. Therefore administration of Fuller's earth is the mainstay of therapy. Fuller's earth is an adsorbent and PQ gets inactivated as soon as it comes in to contact with Fuller's earth. If Fuller's earth is not available activated charcoal can be used (5).

We aimed to look at the adherence to the existing guidelines in the management of PQ poisoning by the ward staff.

\section{Materials and Methods}

A cross-sectional study was conducted at Teaching Hospital, Galle and General Hospital, Matara from June 2008 to June 2010. Consecutive patients admitted to the hospitals due to PQ poisoning confirmed by positive urine sodium dithionite test, were recruited to the study. This study was approved by the Ethical Review Committee, Faculty of Medicine, University of Ruhuna, Sri Lanka.
Informed consent was obtained from the patient or a close relative present at the time of admission if the patient was unable to give the consent.

Current practice of management of PQ poisoning in the two hospitals was compared with the guidelines published by the National Poisons Information Center, National Hospital of Sri Lanka, Colombo.

\section{Results}

There were 145 patients (111 males) admitted with paraquat poisoning to the collaborating hospitals during the study period. The median age of the patient was 29 years (Inter quartile range, 21 - 47).

One hundred and thirty (89.6\%) patients received Fuller's earth. One patient refused the treatment, one patient died before administration of Fuller's earth, the data of administration of Fuller's earth was not available in one patient and 12 patients did not receive Fuller's earth. Among the 12 patients who did not receive Fuller's earth, two patients received activated charcoal. The details of patients who did not receive Fuller's earth are shown in Table 1. Twenty-five patients received both Fuller's earth and activated charcoal.

Table 1: Characteristics of patients who did not receive Fuller's earth

\begin{tabular}{cccc}
\hline Patient & Amount Ingested (ml) & $\begin{array}{c}\text { Duration of Hospital } \\
\text { Stay (days) }\end{array}$ & Outcome \\
\hline 1 & 10 & 3 & Died \\
2 & Unknown & 6 & Left against medical advice \\
3 & No evidence of ingestion & 3 & Discharged \\
4 & Unknown & 13 & Died \\
5 & 5 & 4 & Left against medical advice \\
6 & 5 & 12 & Left against medical advice \\
7 & 15 & 4 & Discharged \\
8 & 3 & 7 & Died \\
9 & 10 & 11 & Discharged \\
10 & $15-30$ & 11 & Discharged \\
11 & Unknown & 1 & Died \\
12 & 750 & 1 & Died \\
\hline
\end{tabular}


Eighty-five out of $130(65.4 \%)$ patients who received Fuller's earth observed Fuller's earth in their stools. One patient died a few hours after the commencement of Fuller's earth. Nineteen (14.6\%) patients did not notice Fuller's earth in their stools. Forty patients either did not observe Fuller's earth passed with their stools or the data was not available.
None of the patient received humidified oxygen except one patient, who was given oxygen at his terminal stage.

The immunosuppression therapy practiced in the collaborating hospitals and the number (\%) of patients who received them are given in Table 2 .

Table 2: Regimens of immunosuppression therapy practiced in the collaborating hospitals

\begin{tabular}{|c|c|c|c|c|}
\hline \multirow[b]{2}{*}{$\begin{array}{c}\text { Immunosuppression } \\
\text { therapy }\end{array}$} & \multicolumn{2}{|c|}{ General Hospital, Matara $(n=61)$} & \multicolumn{2}{|c|}{ Teaching Hospital, Galle $(n=84)$} \\
\hline & Regimen & $\begin{array}{c}\text { Number }(\%) \\
\text { of patients } \\
\text { who received } \\
\text { the treatment }\end{array}$ & Regimen & $\begin{array}{c}\text { Number }(\%) \\
\text { of patients } \\
\text { who received } \\
\text { the treatment }\end{array}$ \\
\hline \multirow[t]{2}{*}{ Cyclophosphamide } & 1g stat (IV) & & $15 \mathrm{mg} / \mathrm{kg} /$ daily & \\
\hline & $\begin{array}{l}250 \mathrm{mg} \text { twice daily } \\
\text { for three days } \\
\text { (oral) }\end{array}$ & $53(87 \%)$ & $\begin{array}{l}\text { for two days } \\
\text { (IV) }\end{array}$ & $31(37 \%)$ \\
\hline Dexamethasone & $\begin{array}{l}8 \mathrm{mg} \text { thrice daily } \\
\text { (oral) }\end{array}$ & $3(5 \%)$ & $\begin{array}{l}8 \mathrm{mg} \text { thrice daily } \\
\text { for } 14 \text { days } \\
\text { (oral) }\end{array}$ & $11(13 \%)$ \\
\hline Methylprednisolone & $\begin{array}{l}1 \mathrm{~g} \text { twice daily for } \\
\text { three days (IV) }\end{array}$ & $53(87 \%)$ & $\begin{array}{l}1 \mathrm{~g} / \text { daily for } \\
\text { three days (IV) }\end{array}$ & $4(5 \%)$ \\
\hline
\end{tabular}

\section{Discussion}

Ninety percent of patients admitted following PQ poisoning received Fuller's earth but at least $15 \%$ of patients did not receive an adequate dose to be detected in the stools. Majority of patients received immunosuppression therapy.

Fuller's earth is the only specific management currently available for paraquat poisoning. Proper administration of Fuller's earth may minimize the mortality and morbidity of patients with paraquat poisoning. The reason for $8 \%$ of patients not receiving Fuller's earth was not clear in the current study. According to the current guidelines, except the patients who did not have evidence of ingestion all others should receive Fuller's earth. According to the expert committee on essential medicines, both Fuller's earth and activated charcoal are included in the National list of Essential Medicines in Sri Lanka. Therefore Fuller's earth and activated charcoal should be available all the time in the hospitals.
Hence all patients with paraquat poisoning should receive Fuller's earth. Activated charcoal can be given if Fuller's earth is not available. Fuller's earth is available as powder for oral suspension. Once it is prepared the supernatant does not contain particles of Fuller's earth. Therefore the suspension has to be well mixed while it is administered. People who give Fuller's earth to patients may not be aware of this fact, so patient may be given the supernatant to take while Fuller's earth may remain at the bottom of the container. This may be a reason why some patients did not observe Fuller's earth in the stools after administration. Proper administration of Fuller's earth has to be emphasized to the patients and care givers.

Chen et ai (2002), Lin J L et al (1999 and 2006) showed promising effects on PQ poisoning with a combination of cyclophosphamide, methylprednisolone and dexamethasone. They used $1 \mathrm{~g}$ of methylprednisolone (IV) daily for three days, 
$15 \mathrm{mg} / \mathrm{kg}$ of cyclophosphamide (IV) daily for two days and preceding $5 \mathrm{mg}$ dexamethasone (IV) three / four times per day or 10mg dexamethasone (IV) thrice daily for 14 days. The dose of methylprednisolone given at the General Hospital, Matara was higher than that in the previous studies. The dose of cyclophosphamide regimen practiced at the two collaborating hospitals were more or less equal to the studies done previously, except the administration of cyclophosphamide via the oral route from the second dose onward at the General Hospital, Matara. The collaborating hospitals in the current study practiced slightly higher doses of oral dexamethasone compared to the previous studies, but the previous studies administered dexamethasone intravenously.

The reason why a smaller percentage of patients received cyclophosphamide \& methylprednisolone at the Teaching Hospital, Galle is that they had been recruited for the double blind placebo controlled immunosuppression trial (Gawarammana I, et al. unpublished data).

\section{Conclusion}

Although $90 \%$ of paraquat poisoned patients received Fuller's earth, either the amount administered or the way of administering was not satisfactory. Proper education of health care personal on administration of Fuller's earth may be required.

\section{Acknowledgements}

We would like to thank the participants, the Consultants who gave their patients for the study, administrative staff and health care professionals at the Teaching Hospital, Galle and the General Hospital, Matara, Heads and the staff members of the Department of Pharmacology and the Department of Medicine, Faculty of Medicine, University of Ruhuna, Sri Lanka, and the members and the Clinical Research Assistance of the South Asian Clinical Toxicology Research Collaboration. A special word of thanks is extended to Professor N.A. Buckley, Professor A.H. Dawson, Professor K.D. Pathirana, Professor P.L. Ariyananda and Dr. Bilesha Perera.

\section{Source of funding}

This study was supported by a Welcome Trust and NHMRC International Collaborative Research Grant(GR071669MA).

\section{References}

1. Dart RC, McGuigan MA. Pesticides. Philadelphia: Lippincott Williams and Wilkins; 2004.

2. Wilks MF, Tomenson JA, Fernando R, et al. Formulation changes and time trends in outcome following paraquat ingestion in Sri Lanka. Clin Toxicol (Phila) 2008; 49(1): 21-8.

3. Gawarammana IB, Dawson AH. Peripheral burning sensation: a novel clinical marker of poor prognosis and higher plasma-paraquat concentrations in paraquat poisoning. Clin Toxicol (Phila) 2010; 48(4): 347-9.

4. Senarathna L, Eddleston M, Wilks MF, et al. Prediction of outcome after paraquat poisoning by measurement of the plasma paraquat concentration. QJM 2009; 102(4): 251-9.

5. Fernando R. Paraquat. Management of poisoning. National Poisons Information Center. Sri Lanka 2007: 52-6.

6. Scherrmann JM, Houze P, Bismuth C, et al. Prognostic value of plasma and urine paraquat concentration. Hum Toxicol 1987; 6(1): 91-3.

7. Yamashita J. Clinical studies on paraquat poisoning; prognosis and severity index of paraquat poisoning using the urine levels. Nippon Hinyokika Gakkai Zasshi 1989; 80(6): $875-83$.

8. Chen GH, Lin JL, Huang YK. Combined methylprednisolone and dexamethasone therapy for paraquat poisoning. Crit Care Med 2002; 30(11): 2584-7.

9. Lin JL, Leu ML, Liu YC, et al. A prospective clinical trial of pulse therapy with glucocorticoid and cyclophosphamide in moderate to severe paraquat-poisoned patients. Am J Respir Crit Care Med 1999; 159(2): 357-60.

10. Lin JL, Lin-Tan DT, Chen KH, et al. Repeated pulse of methylprednisolone and cyclophosphamide with continuous dexamethasone therapy for patients with severe paraquat poisoning. Crit Care Med 2006; 34(2): 368-73. 